\title{
Five-in-one Connotation Promotion Pattern of Information Management and Information System*
}

\author{
Yan He, Liu Jie \\ College of Computer Science, Chongqing University of Technology, Chongqing 400054, China \\ yanhe@cqut.edu.cn, 954985351@qq.com
}

\begin{abstract}
In order to meet the demand of reform and development of higher education in the new situation, a new professional connotation promotion pattern of information management and information system, namely five-in-one ,is constructed systematically from the following aspects: optimizing personnel training programs, constructing teachers, reforming teaching contents and curriculum system, reforming practice teaching system, integrating teaching with scientific research. Adhere to the purposes of "grasping quality, improving the educational level, building featured, creating brand and Seeking developmens", we will comprehensively improve the quality of personnel training to train high quality applied professionals for local economic construction.

Index Terms - five-in-one, professional connotation, promotion pattern
\end{abstract}

\section{Introduction}

In the 2lst century, higher education in our country has realized the historical leap from past traditional elite education to public education. It is stepping into an stage of comprehensively improving quality after the great leap development[1]. "Constantly improving the quality is the lifeline of higher education, and we must always run through all work of the higher school ,such as personnel cultivation, scientific research, social services, cultural inheritance innovation", as Hu Jintao pointed out in his important speech at Tsinghua university centennial conference. Higher education connotation development is that comprehensively improving the teaching quality, and providing a strong knowledge and talent support for the rapid and sustainable development of economy and society where quality is its foothold and goal. How to ensure and improve the quality of talent cultivation, and realize the coordinated development of scale and quality has become the realistic problem for the further development of higher esucation[2]

In the long term, information management and information system (IMIS) in our school conforms to the interdisciplinary talents cultivation mode of modern management science based, information technology focused , combining the information management with the development of information system, and focusing on cultivating the ability of information system development, forming some distinct characteristics. During the nearly 20 years ever since the enrollment of the major, our school has trained a large number of information management and information technology development personnels for the society, and has a good $\mathrm{s}$ reputation in the society. But the specialty construction can not be stuck in the past, it is necessary to keep up with the pace of the times. only constantly enhance the connotation of professional development and further condense professional characteristics, can our school provide a strong knowledge and talent support for the rapid and sustainable development of the economy and society. As a result, research of the connotation of the professional promotion mode is of great significance.

\section{Optimizating Talent Training Programs Is the Basis of the Professional Connotation Promotion}

Based on the policy guiding of national information industry development planning and Chong qing's promoting the development of IT industry, combined closely with the international gradually developing engineering certification of education of information technology talents related in order to cultivate more information management and information systems professional talents with high quality and strong ability of practice for our country. This major will further strengthen the contact with the industry, further make a deep research, accurately grasp the social and industry development needs, optimize the talent training scheme and reform personnel training mode with purpose.

A. Conducting extensive research, and keeping close contact and communication with industry

To strengthen the contact with the industry, conduct a research extensively, grasp the characteristics and trends of the industry's demand for talent, adjust and optimize the scheme of talent cultivation in time.

\section{B. Promoting the reform of credit system, and optimizing the structure of teaching module continuedly.}

To merge related course modules, integrate and optimize curriculum system to build three platforms which contain a public course platform, subject foundation platform and specialized course platform in line with "promoting the reform of credit system, grasping the solid basic knowledge, focusing on the coordinated development of the knowledge, ability and quality, constructing reasonable professional backbone courses and practical teaching system, and cultivating high-quality innovative talents". The public course platform contains public required course module and public elective course module, the discipline basic course platform contains disciplines (professional) compulsory courses module and subject elective

\footnotetext{
* This work is partially supported by NSFC Grant \#61173184 to Yan He.
} 
courses module, and the specialized course platform contains professional compulsory course module and professional elective course module.

\section{Consolidating and improving further the three-in-one personnel training system of "knowledge, ability and quality"}

To cultivate students in the aspects of knowledge, ability, quality for the society and industry development goals by the master of the basic knowledge, the cultivation of the system and engineering application ability, and professional quality, so as to meet the social demand for information management and information system professional talents and improve the employment rate and quality of graduates and employment.

\section{Emphasis on the second classroom to enhance students' comprehensive ability.}

To further make a good use of the second class to improve the students' innovative spirit and comprehensive ability. Through the popular science and technology competition, such as mathematical modeling contest, program designing competition and the database designing competition and so on, to motivate the students' scientific research enthusiasm, stimulate students' innovation spirit, cultivate students expertise, and train the students' skill and ability of analyzing problems, solving problems and the integrated use of knowledge to improve students' comprehensive quality.

\section{E. Emphasis on student development, implementation of individualized training, training top-notch talent}

The four-year program is divided into two parts, one part is the basic plan which is conducive to cultivate innovation spirit for all the students, the second part is to implement a comprehensive plan, which is conducive to the development of personality for the students with spare capacity, such as minor in plan, double degrees, innovation ability enhancement plan, foreign language enhancement plan and so on. To further strengthen supervisory system training and provide tutors for more undergraduate students to guide students to participate in scientific research, cultivate and enhance students' scientific research ability.

\section{Reforming Teaching Content and Course System Is the Soul of Professional Connotation[3]}

This paper puts emphasis on construction of professional core courses and with the demonstrational national superior course, the municipal high quality course, and school curriculum, continuously strengthen the construction of teaching materials to improve the quality of curriculum construction in an all-round way, continuously optimize the curriculum system, absorb advanced course construction and reform experience, constantly track the professional technology development and new technology hot spot, and update, supplement the course content in due course. strengthen the construction of case, improve students' comprehensive ability, guide and inspire students' positive innovation through the implementation of the comprehensive case teaching and practice[4]; Constantly promote the scientific research results to make it become the teaching resources, improve the teaching effect, and further improve five-step teaching method where step one, interpreting the basic knowledge; step two, comprehensive teaching case; step three, intensive training; step four, summarization; step five, project practice teaching method to improve the teaching quality effectively.

To strengthen curriculum group construction on the basis of the occupation post, constantly optimize the curriculum system to adapt to IT industry development requirements , stimulate the students' initiative with the maximum and improve the engineering quality and hands-on ability of graduates.

To strengthen construction of teaching material and selection of excellent teaching material. In order to guarantee excellent teaching material stepping into the classroom, in line with the principles of the new system, the new content, the new method to realize option combined with writing where the former is first, the latter is second. To give priority to the selection of excellent teaching material published by the state and write teaching materials with characteristics combining with the actual situation of this major. At the same time, to write the teaching material of the emerging discipline and edge discipline curriculum to make up for the blank materials according to the requirements of the construction of professional (course). To write the auxiliary materials which are matching to professional backbone courses, such as experiment instruction, curriculum design instruction, test question library and so on. The network teaching is realized gradually by making use of multimedia teaching means while the teaching material is adopted.

\section{Reforming Practice Teaching System Is the Key for Professional Connotation Promotion}

The practice teaching content of cultivating the students' ability of analysis, problem solving and innovation ability as well as the development of creative thinking is researched and developed continuously to further cultivate the students' practical ability and innovation ability.

The practice teaching project of the all-round and multi-type is constructed. In order to improve the the traditional experiment teaching problems, such as the poor contact of theory and experiment, the poor application effects of the students and so on, experimental practice project are developed with several levels, such as basic verification type, comprehensive design type and open innovative type and so on. To cultivate students' comprehensive engineering quality and practical professional skills by more complete engineering case teaching, In the aspect of training the students' beginning ability and engineering quality, a large number of case libraries in professional direction is developed and enriched.

Perfect multi-level practical teaching system. Cultivate students' ability to apply information technology to engineering practice step by step and purposefully from classroom experiment to curriculum design, complete case, enterprise practice, graduation design (real project). Implementation of the comprehensive cooperation between colleges and enterprises to make IT companies involved in the whole process 
of the practice teaching effectively, developing the students' vocational quality and skills.

The scientific research platform should be strengthen further. To provide the good basic condition for the students to participate in the teachers' scientific research and extracurricular activities of science and technology, scientific research facilities including software and hardware platform construction and management system should be further strengthened, and the utilization efficiency of teaching and research facilities should be improved.

The practical teaching platform also should be strengthen further. To strengthen the construction of To increase capital investment, and improve all kinds of practical teaching facilities. In order to build professional technical development lab, experimental teaching equipment with comprehensive characteristics, designment and innovation should be escalated. To build perfect lab system of covering large database system branches, such as information security, information resource organization and management and so on, ERP comprehensive laboratory, large database technology lab and information security laboratory construction should be strengthened firstly.

To further strengthen construction of practice base. On the basis of the current eight off-campus practical teaching base, according to the needs of the professional development, this major will also further strengthen the construction of practice base working with other high-tech enterprise on enterprise information and information security industry to build a batch of off-campus practice bases integrating technical cooperation, " $3+1$ " education mode and employment .

\section{Constructing Teachers Is the Core Content of the Professional Connotation.}

To introduce some professional directions with advantages and high-level professionals with strong engineering backgrounds. According to some requirements determined by this profession that attaching large importance to develop enterprise information, information security and maintenance, systems integration and project management, software outsourcing technology with some advantage, some measures should be actively taken to establish incentives and environment in order to introduce, select, train and use some high-level talents.

To strengthen internal training system. Actively introduce talents, meanwhile, strengthen the training of the existing young teachers and improve their ability, enhancing their ability in teaching, research and other aspects, through a variety of training and education at home and abroad, etc. Especially, enhance teachers' ability to develop applications teaching the front-line professional courses, promoting their practical experience in the development, undertaking the professional core courses burden of teaching and research, becoming the backbone of training graduates meeting the social needs. Continue to optimize the internal mentoring of young teachers and encourage the professional teachers to pursue a $\mathrm{PhD}$ so as to receive the domestic first-class university education. Select the young teachers to participate in various teacher training, in addition, teachers are encouraged to participate in international academic and educational exchanges and other forms, greatly improving the knowledge, academic levels, teaching and research capabilities of the teaching team.

\section{Integrating Scientific Research with Teaching Is the Effective Guarantee for the Sustainable Development of Professional Connotation Promotion}

To instruct professional teachers conduct scientific research and teaching research through policy encouragement and youth tutor system .Through combining the "Twelfth five-year" science and technology development plan of chong qing closely, as well as the higher educational development plan, to choose a breakthrough point depending on our own team and research condition, treating it as a support point, dominant directions will be well developed, academic exchange, together with teaching research and reform will be strengthened. Inquiring into the new teaching method and means can help further improve the teaching methods, such as objective teaching method and "Case driving, iterative experience". Thus, The major research and teaching will achieve a full development. Strengthening the construction of research base, eventually, making it one of scientific research, teaching and research, as well as the talent training bases with high level.

\section{Acknowledgment}

This work is supported by National Natural Science Foundation of China (NO. 61173184) and the Graduate Innovation Foundation of Chongqing University of Technology (NO. YCX2013219)

\section{References}

[1] Zhou Ji, "our country's higher education has realized the historical leap", http://edu.people.com.cn/GB/7021274.html (2008/03/19)

[2] China education news commentator, "Quality is the lifeline of higher education, which is conference spirit of study comprehensively improve the quality of higher education work", http://www.moe.gov.cn/publicfiles/business/htmlfiles/moe/s6414/20120 3/132985.html (2012/03/24).

[3] Peng Qing-long, "Needs, Featureds and quality". Contemporary Foreign Languages Studies, 2012, 2(2):43-48.

[4] Cheng Jing, Liang Fu-cheng. "Research on development strategy of colleges and universities undergraduate professional connotation", Theory and Practice of Contemporary Education. 2012, 9(4): 44-45. 